\title{
TCOM \\ Animals of Instagram: taxonomic bias in science communication online
}

\section{Grace Heathcote}

\begin{abstract}
There are currently no published studies examining taxonomic bias on Instagram. To address this knowledge gap, this study examined seven popular science communication accounts for a year and found that the majority of posts featured vertebrates. However, non-insect invertebrates attracted the highest measures of positive audience engagement (likes, views and comments), suggesting a mismatch between the preferences of science-seeking audiences online and the information being offered to them. These results challenge traditional notions of charismatic megafauna and could improve conservation outcomes of traditionally under-represented species like invertebrates.
\end{abstract}

Keywords

Environmental communication; Public engagement with science and technology; Science and media

DOI

https://doi.org/10.22323/2.20040210

Submitted: 16th October 2020

Accepted: 18th May 2021

Published: 29th July 2021

Against a background of global accelerated biodiversity loss [Ceballos et al., 2015; Dirzo and Raven, 2003], the need to study, protect and raise awareness of the remaining biodiversity is urgent [Donaldson et al., 2017; Velasco et al., 2015]. However, such efforts often only focus on a small subset of species while others continue to be overlooked [Cronin et al., 2014]. This pattern, known as taxonomic bias or taxonomic chauvinism, is pervasive and has been documented across academic research and associated peer-reviewed publications [Clark and May, 2002; Cronin et al., 2014; Donaldson et al., 2017], news media [Clucas, McHugh and Caro, 2008; Lunney and Matthews, 2003; Lyngdoh, Dixit and Sinha, 2017], conservation funding [Clark and May, 2002; Veríssimo et al., 2017], policy protections for threatened species [Kidd et al., 2018] and on social media [Kidd et al., 2018; Llewellyn and Rose, 2021; Roberge, 2014]. Across these formats, vertebrates, particularly mammals and birds, have consistently been favoured more strongly than invertebrates [Di Marco et al., 2017; Fazey, Fischer and Lindenmayer, 2005; Lawler et al., 2006; Rosenthal et al., 2017; Titley, Snaddon and Turner, 2017; Velasco et al., 2015]. 
Bias in research effort may lead to deficiencies in the understanding or reporting of conservation needs and therefore a reduced ability to discover, better understand and mitigate risks to less-well-known but equally important species [Donaldson et al., 2017; Titley, Snaddon and Turner, 2017]. Further, taxonomic bias in the division of conservation funding [Martín-López et al., 2009] and direction of policy protections [Walsh et al., 2013] creates a loop in which conservation efforts are fed back to those species whose threats are already well understood [Martín-López et al., 2009; Titley, Snaddon and Turner, 2017]. This system makes it difficult to identify when under-represented species become threatened or extinct, to predict future losses or to recognise impacts on the functioning of global ecosystems [Titley, Snaddon and Turner, 2017; Velasco et al., 2015].

Links between public opinion and the direction of scientific research, conservation funding and implementation of conservation policies are well established [Davies et al., 2018; Martín-López et al., 2009; Troudet et al., 2017]. The power of public opinion also means that the less-well-known or less popular species are likely to hold lower societal conservation priority [Davies et al., 2018; Donaldson et al., 2017; dos Santos et al., 2020; Jarić et al., 2019], which raises concerns for threatened species which do not enjoy a high or positive public profile [Donaldson et al., 2017]. As a result, communicating the conservation needs of a diversity of taxa to the general public is becoming increasingly important in order to foster engagement with and support for these species [Davies et al., 2018; Jarić et al., 2019; McClain, 2019; Rose, Hunt and Riley, 2018; Velasco et al., 2015].

Takahashi and Tandoc [2016] found that people with an existing interest in science prefer to use the Internet to seek information, with this medium displacing traditional sources of science information such as news media, books and museums. Indeed, the Internet offers a wealth of opportunities for the communication and learning of science including easy availability, a diversity of platforms and the potential for public participation in scientific discourse and content creation [Lörcher and Taddicken, 2017]. One of the best-known tools in online communication is social media, with over 70 per cent of Americans ever having used some form of social media [Auxier and Anderson, 2021] and over half reporting that they receive news on social media [Shearer, 2021]. Social media usage is on the rise, with the number of people engaging online increasing steadily since the start of the decade [Pew Research Center, 2021]. As such, social media is emerging as a powerful tool for science to be communicated directly to the public [Barel-Ben David, Garty and Baram-Tsabari, 2020; Jarreau, Dahmen and Jones, 2019].

Most social media users report seeing science-related content, but this is mostly by chance and over half of these users distrust the information presented [Funk, Gottfried and Mitchell, 2017]. This highlights a need for scientists and science communicators to become more engaged online to combat issues of low public science literacy and community mistrust in science [McClain, 2019]. While the use of social media in conservation science is in its infancy [Di Minin, Tenkanen and Toivonen, 2015], scientists and science organisations are increasingly adopting it as a tool to exchange information [Collins, Shiffman and Rock, 2016; Papworth et al., 2015], bypass low rates of research coverage in traditional news media [Baker et al., 2012], adapt to globally declining rates of science journalism [Barel-Ben David, Garty and Baram-Tsabari, 2020], broaden the size and diversity of their audiences 
as well as find potential collaborations [Barel-Ben David, Garty and Baram-Tsabari, 2020; Jarreau, Dahmen and Jones, 2019].

In addition, social media allow two-way communication between scientist and the public that aims to engage as well as inform [McKinnon et al., 2018; Papworth et al., 2015], encouraging public awareness and uptake of calls-to-action [Pavelle and Wilkinson, 2020]. Content is tailored to users interests through embedded algorithms, helping to reach new audiences and spread content beyond the network of the original poster [Pavelle and Wilkinson, 2020]. This can foster effective science communication by guiding users to "reflect upon new ideas [and] inform or review previously held opinions" [Pavelle and Wilkinson, 2020, p. 5].

One of the fastest-growing social media platforms is Instagram [Pew Research Center, 2021]. Launched in October 2010 it now boasts over a billion monthly users worldwide and is only surpassed by Facebook and YouTube [Statista, 2021]. A Pew Research Center survey in 2020 found that 40 per cent of American adults had ever used Instagram, with the majority of these users visiting the site daily [Auxier and Anderson, 2021]. The platform focuses on the sharing of images and short videos, which have been recognised as playing an important role in effective communication by capturing audience attention and increasing the time spent on the platform [Russmann and Svensson, 2016]. This popularity, ease-of-access and visual nature makes Instagram an ideal platform for science communication and learning. In addition, Instagram features other factors useful for learning such as the sharing of user-generated content, allowing searches for information via hashtags, and interaction through captioning and comments [Jarreau, Dahmen and Jones, 2019; Pavelle and Wilkinson, 2020].

\section{Objective}

Research into the relationship between science communication and social media is still emerging, particularly on Instagram [Pavelle and Wilkinson, 2020; Russmann and Svensson, 2016]. In fact, a literature review yielded no published academic research examining taxonomic bias in science communication on Instagram. Considering the power of imagery for wildlife conservation [Hansen and Machin, 2013; Papworth et al., 2015], this is surprising, and highlights a knowledge gap with two associated research questions:

Q1. Is taxonomic bias present in the content posted by science communication accounts on Instagram?

Q2. Is taxonomic bias present in the public engagement with these Instagram posts?

Methods

The Instagram feeds of seven science communication accounts were examined which, as of May 2020, together had almost 1.8 million followers (Table 1). A longlist of potential accounts was compiled by searching for the keywords 'science' and 'nature' among the accounts on Instagram. These were then shortlisted against several pre-determined criteria: being instructional or educational in purpose, having a global focus, promoting multi-species wildlife, and having strong Instagram followings (more than 70,000 followers). These 
Table 1. Instagram accounts used in the study (and number of followers as at May 2020).

\begin{tabular}{|llccc|}
\hline Account name & Agency & $\begin{array}{c}\text { Number of } \\
\text { followers (May } \\
\text { 2020) (in'000s) }\end{array}$ & $\begin{array}{c}\text { Total number } \\
\text { of posts }\end{array}$ & $\begin{array}{c}\text { Number of } \\
\text { animal posts }\end{array}$ \\
\hline csirogram & $\begin{array}{l}\text { Commonwealth } \\
\text { Scientific and Industrial }\end{array}$ & 73.3 & 675 & 355 \\
& $\begin{array}{l}\text { Research Organisation } \\
\text { (Australia) }\end{array}$ & & & \\
iflscience & IFLScience & 457 & 1761 & 701 \\
nature.portfolio & Nature Portfolio & 120 & 92 & 18 \\
newscientist & New Scientist & 243 & 293 & 68 \\
popsci & Popular Science & 109 & 144 & 27 \\
sciencealert & Science Alert & 693 & 366 & 120 \\
sciencemagazine & Science Magazine & 96.7 & 112 & 24 \\
& Visuals Team & & & $\mathbf{1 3 1 3}$ \\
\hline
\end{tabular}

criteria were established to reduce potential geographic and cultural biases. A mix of academic and news/popular oriented accounts was included in order to capture a broad science-interested audience base.

A coding system to ensure systematic recording of each post was determined before image data were analysed. Examples include:

- Only the first image to be recorded when a post carried an album of multiple images

- Only the visually dominant species (i.e., the animal most apparent to the viewer) to be recorded when two animals were featured in an image (e.g., a honeybee carrying a mite - the honeybee was recorded)

Posts that were not animal-related were recorded as 'other' and excluded from statistical analysis. Examples include:

- Images that did not include an animal, even if the text discussed animal-related issues (e.g., a map of a journey taken by an arctic fox, large spider webs covering trees and tables). This included posts on astronomy, infrastructure, history, geology, fungi, weather, plastic pollution and flora.

- Images of internal details or processes (e.g., cells, internal organs)

- Dinosaurs and other prehistoric animals

- Images of humans, unless a non-human animal was also in the image

- Cartoons, memes and comics, even when of animals

All posts between January 1 and December 31, 2019 were examined from each account. Following Papworth et al. [2015], Lessard, Whiffin and Wild [2017] and Toivonen et al. [2019], levels of engagement were recorded as the number of likes (photos), views (videos) and comments for each post. Each was then standardised 
by dividing the total of each metric per taxa by the number of recorded posts per taxa. These data were captured during April and May 2020, more than four months after the last post. This timeframe is considered sufficient to have allowed engagement (i.e., likes, views and comments) to peak [McClain, 2019; Papworth et al., 2015].

Data from all seven accounts were recorded in a Microsoft Excel spreadsheet, noting account name, date of post, common name of species, scientific name of species (where possible), phylum, subphylum/class, number of likes/views and number of comments. Instagram records the number of 'likes' for photos and the number of 'views' for videos. As such, these were analysed independently. In most cases, animals were classified to their class. Where insufficient information was provided in the post, animals were classified to their phylum or sub-phylum (including crustacea, platyhelminthes, tardigrada, nematoda, ctenophora, nemertea and rotifera). Species were grouped according to their respective phylum/class and a mean number of likes, views and comments per post was calculated for each. Several subphyla and classes returned very small numbers of posts (i.e., less than five posts) and so were combined with others in the same phylum for some statistical analyses. The frequency and proportion of posts per taxa were calculated for the dataset. Chi-square analysis was used to determine whether differences between the number of posts per taxa and between likes and comments across taxa were statistically significant.

To examine public reaction to the posts in more depth, a sentiment analysis of comments was conducted. To do this, an online random-number generator (www.calculator.net/random-number-generator.html) was used to select $20 \%$ of all posts (approximately 262 posts). The first ten comments from each of these target posts were used in the analysis. Only the first (primary) comment from a thread was taken unless there were less than ten primary comments on the post, in which case replies to the first comment were recorded, and so on, until ten "suitable" comments were obtained. A classification system was created to define which comments were unsuitable for inclusion in the study. Examples of those not included are:

- Tags of people or accounts

- Any comment not in English (to avoid mistranslations)

- Marketing or advertising

- Identical comments on the same post (with only the first included)

Emojis were included and were coded similarly to text comments.

To ensure coding was consistent, the Word-Emotion Association Lexicon developed by the National Research Council of Canada [Mohammad, 2010] was used. Then, following guidelines provided by Toivonen et al. [2019], these target comments were manually coded as negative, positive, neutral or undetermined, with each comment given a sentiment score of either -1 (negative), 0 (neutral or undetermined), or 1 (positive). This then allowed a mean sentiment score for each phylum/class to be calculated. Chi-square analysis was used to determine whether 
differences between the mean sentiment score for each phylum/class were statistically significant.

A total of 3443 posts were recorded across the seven Instagram accounts, of which 1313 were animal related (Table 1). Of these, 961 were photos and 352 were videos.

Overall, $61.54 \%(n=808)$ of posts were about vertebrates and $38.46 \%(n=505)$ were about invertebrates. Mammals accounted for $29.86 \%(n=392)$ of posts, insects for $14.09 \%(n=185)$, birds for $11.58 \%(n=152)$, and reptiles for $7.39 \%$ $(n=97)$. Fewer posts covered bony fish $(5.71 \%, n=75)$, cnidarians and arachnids $(3.96 \%, n=52)$, cephalopods $(3.88 \%, n=51)$, cartilaginous fish $(3.35 \%, n=44)$, crustaceans $(3.27 \%, n=43)$, and amphibians $(3.27 \%, n=43)$. Smaller proportions (less than 3\% each) were found for fifteen other invertebrate taxa as well as for hagfish, African lungfish (Protopteridae) and lampreys (Table 2).

\section{Photos}

The most frequent taxa in photo posts were mammals $(n=291,30.28 \%)$, insects $(n=155,16.13 \%)$, birds $(n=130,13.53 \%)$, reptiles $(n=73,7.60 \%)$, bony fishes $(n=54,5.62 \%)$, and arachnids $(n=38,3.95 \%)$ (Table 3$)$.

Several subphyla/classes returned very small numbers of posts (i.e., less than five). To allow statistical analysis, the oligochaeta and polychaeta were combined as the annelida (final $n=10$ ), and the crinoidea, echinodermata, asteroidea, echinoidea, asterozoa were combined as the echinodermata (final $n=10$ ). Taxa with fewer than 10 photo posts were excluded from analysis in order to avoid potential outlier bias. This approach retained $96.7 \%$ of the original photo data for statistical analysis.

Chi-square analysis showed that differences in the number of posts between taxa with 10 or more photo posts was significant $\left(c^{2}[\mathrm{df}=14, n=931]=1325\right.$, $p \leq 0.0005)$. That is, taxa such as mammals, insects and birds had significantly more photo posts than other taxa.

Considering only the taxa with more than 10 photo posts, the images with the highest number of likes per post were of cephalopods (3151 likes per post, range 958 to 6446 likes), reptiles (3071 likes per post, range 381 to 24158 likes), mammals (3047 likes per post, range 267 to 14232 likes), amphibians (3035 likes per post, range 343 to 9677 likes), and arachnids (2775 likes per post, range 412 to 11898 likes) (Table 3). Differences in the number of likes per post were significant $\left(c^{2}[\mathrm{df}=14, n=931]=1029, p \leq 0.0005\right)$, indicating a significantly higher level of audience engagement (via likes per post) for photos of taxa such as cephalopods, reptiles, mammals and amphibians.

The images with the highest number of comments per post were of arachnids (55.9 comments per post, range 8 to 180 comments), amphibians (53.4 comments per post, range 1 to 376 comments), echinoderms (52.5 comments per post, range 2 to 173 comments), mammals ( 52.5 comments per post, range 0 to 530 comments), annelids (47.2 comments per post, range 3 to 314 comments), and reptiles (42.4 comments per post, range 0 to 339 comments) (Table 3 ). Differences in the number 
Table 2. Frequency and proportion of Instagram posts by taxa against average proportion of taxa found in studies of taxonomic bias in the academic literature.

\begin{tabular}{|c|c|c|c|c|}
\hline & $\begin{array}{l}\text { Frequency of } \\
\text { Instagram } \\
\text { posts }\end{array}$ & $\begin{array}{l}\% \text { of total } \\
\text { Instagram } \\
\text { posts }\end{array}$ & $\begin{array}{c}\text { Average \% of } \\
\text { published } \\
\text { papers }^{1}\end{array}$ & $\begin{array}{c}\% \text { of known } \\
\text { animal species }\end{array}$ \\
\hline \multicolumn{5}{|l|}{ Vertebrates } \\
\hline Mammalia & 392 & $29.81 \%$ & $25.29 \%$ & $0.52 \%$ \\
\hline Aves & 152 & $11.56 \%$ & $25.60 \%$ & $0.93 \%$ \\
\hline Reptilia & 97 & $7.38 \%$ & $3.38 \%$ & $0.88 \%$ \\
\hline Actinopterygii & 75 & $5.70 \%$ & & $2.85 \%$ \\
\hline Chondrichthyes & 44 & $3.35 \%$ & & $0.10 \%$ \\
\hline Amphibia & 43 & $3.27 \%$ & $2.89 \%$ & $0.58 \%$ \\
\hline Hyperoartia & 3 & $0.23 \%$ & & \\
\hline Myxini & 1 & $0.08 \%$ & & $0.01 \%$ \\
\hline \multirow[t]{2}{*}{ Protopterus } & 1 & $0.08 \%$ & & $0.0004 \%$ \\
\hline & 808 & $61.54 \%$ & & \\
\hline \multirow[t]{2}{*}{$\begin{array}{l}\text { Fish (includes } \\
\text { actinopterygii, } \\
\text { chondricthyes, } \\
\text { hyperoartia, myxini } \\
\text { and protopterus) }\end{array}$} & 124 & $9.43 \%$ & $6.01 \%$ & \\
\hline & & & $67.80 \%$ & \\
\hline \multicolumn{5}{|l|}{ Invertebrates } \\
\hline Insecta & 185 & $14.09 \%$ & $13.13 \%$ & $72.82 \%$ \\
\hline Arachnida & 52 & $3.96 \%$ & & $6.23 \%$ \\
\hline Cnidaria & 52 & $3.96 \%$ & & $0.92 \%$ \\
\hline Cephalopoda & 51 & $3.88 \%$ & & $0.05 \%$ \\
\hline Crustacea & 43 & $3.27 \%$ & & $2.54 \%$ \\
\hline Gastropoda & 36 & $2.74 \%$ & & $2.71 \%$ \\
\hline Echinodermata & 18 & $1.37 \%$ & & $0.60 \%$ \\
\hline Tardigrada & 15 & $1.14 \%$ & & $0.09 \%$ \\
\hline Annelida & 14 & $1.07 \%$ & & $1.18 \%$ \\
\hline Bivalva & 7 & $0.53 \%$ & & $0.79 \%$ \\
\hline Diplopoda & 6 & $0.46 \%$ & & $1.09 \%$ \\
\hline Tunicata & 5 & $0.38 \%$ & & \\
\hline Nematoda & 5 & $0.38 \%$ & & $0.31 \%$ \\
\hline Ctenophora & 3 & $0.23 \%$ & & $0.01 \%$ \\
\hline Plankton & 3 & $0.23 \%$ & & \\
\hline Platyhelminthes & 3 & $0.23 \%$ & & $0.84 \%$ \\
\hline Rotifera & 3 & $0.23 \%$ & & $0.18 \%$ \\
\hline Pycnogonida & 2 & $0.15 \%$ & & $0.11 \%$ \\
\hline \multirow[t]{2}{*}{ Nemertea } & 2 & $0.15 \%$ & & $0.11 \%$ \\
\hline & 505 & $38.46 \%$ & & \\
\hline \multirow[t]{2}{*}{ Non-insect invertebrates } & 320 & $24.37 \%$ & $5.36 \%$ & \\
\hline & & & $15.19 \%$ & \\
\hline
\end{tabular}

${ }^{1}$ Clark and May [2002], Cronin et al. [2014], Di Marco et al. [2017], Fazey, Fischer and

Lindenmayer [2005], Lawler et al. [2006], Martín-López et al. [2009], Rosenthal et al. [2017],

Titley, Snaddon and Turner [2017] and Velasco et al. [2015].

2 Roskov et al. [2019]. 
Table 3. Number of posts, likes and comments on photos for each taxa, arranged from lowest to highest number of posts per taxa.

\begin{tabular}{|c|c|c|c|c|c|c|c|}
\hline Phylum & Subphylum/Class & $\begin{array}{c}\# \\
\text { posts }\end{array}$ & $\begin{array}{l}\% \text { of } \\
\text { total } \\
\text { posts }\end{array}$ & $\begin{array}{l}\text { Total } \\
\text { likes }\end{array}$ & $\begin{array}{c}\text { Likes } \\
\text { per } \\
\text { post }\end{array}$ & $\begin{array}{c}\text { Total } \\
\text { com- } \\
\text { ments }\end{array}$ & $\begin{array}{c}\text { Comments } \\
\text { per post }\end{array}$ \\
\hline Echinodermata & Crinoidea & 1 & $0.10 \%$ & 873 & 873.00 & 2 & 2.00 \\
\hline Echinodermata & Echinodermata & 1 & $0.10 \%$ & 1891 & 1891.00 & 23 & 23.00 \\
\hline Echinodermata & Echinozoa & 1 & $0.10 \%$ & 1839 & 1839.00 & 73 & 73.00 \\
\hline Chordata & Hyperoartia & 2 & $0.21 \%$ & 6829 & 3414.50 & 93 & 46.50 \\
\hline Nematoda & Nematoda & 2 & $0.21 \%$ & 4000 & 2000.00 & 83 & 41.50 \\
\hline Nemertea & Nemertea & 2 & $0.21 \%$ & 1183 & 591.50 & 21 & 10.50 \\
\hline Platyhelminthes & Platyhelminthes & 2 & $0.21 \%$ & 6308 & 3154.00 & 156 & 78.00 \\
\hline Tardigrada & Tardigrada & 2 & $0.21 \%$ & 5627 & 2813.50 & 187 & 93.50 \\
\hline Annelida & Oligochaeta & 3 & $0.31 \%$ & 3919 & 1306.33 & 81 & 27.00 \\
\hline Ctenophora & Ctenophora & 3 & $0.31 \%$ & 7713 & 2571.00 & 146 & 48.67 \\
\hline Echinodermata & Asterozoa & 3 & $0.31 \%$ & 10075 & 3358.33 & 250 & 83.33 \\
\hline Various & Various & 3 & $0.31 \%$ & 1538 & 512.67 & 16 & 5.33 \\
\hline Echinodermata & Asteroidea & 4 & $0.42 \%$ & 9099 & 2274.75 & 177 & 44.25 \\
\hline Mollusca & Bivalva & 4 & $0.42 \%$ & 4483 & 1120.75 & 60 & 15.00 \\
\hline Arthropoda & Diplopoda & 5 & $0.52 \%$ & 7080 & 1416.00 & 71 & 14.20 \\
\hline Chordata & Tunicata & 5 & $0.52 \%$ & 14573 & 2914.60 & 239 & 47.80 \\
\hline Annelida & Polychaeta & 7 & $0.73 \%$ & 21731 & 3104.43 & 391 & 55.86 \\
\hline Cnidaria & Medusozoa & 10 & $1.04 \%$ & 20290 & 2029.00 & 267 & 26.70 \\
\hline Cnidaria & Anthozoa & 21 & $2.19 \%$ & 34042 & 1621.05 & 419 & 19.95 \\
\hline Mollusca & Cephalopoda & 22 & $2.29 \%$ & 69331 & 3151.41 & 766 & 34.82 \\
\hline Mollusca & Gastropoda & 22 & $2.29 \%$ & 54388 & 2472.18 & 812 & 36.91 \\
\hline Arthropoda & Crustacea & 30 & $3.12 \%$ & 82523 & 2750.77 & 1227 & 40.90 \\
\hline Chordata & Chondrichthyes & 31 & $3.23 \%$ & 75714 & 2442.39 & 918 & 29.61 \\
\hline Chordata & Amphibia & 34 & $3.54 \%$ & 103181 & 3034.74 & 1816 & 53.41 \\
\hline Arthropoda & Arachnida & 38 & $3.95 \%$ & 105430 & 2774.47 & 2126 & 55.95 \\
\hline Chordata & Actinopterygii & 54 & $5.62 \%$ & 130101 & 2409.28 & 1701 & 31.50 \\
\hline Chordata & Reptilia & 73 & $7.60 \%$ & 224152 & 3070.58 & 3096 & 42.41 \\
\hline Chordata & Aves & 130 & $13.53 \%$ & 303630 & 2335.62 & 4501 & 34.62 \\
\hline Arthropoda & Insecta & 155 & $16.13 \%$ & 347400 & 2241.29 & 5301 & 34.20 \\
\hline Chordata & Mammalia & 291 & $30.28 \%$ & 886518 & 3046.45 & 15267 & 52.46 \\
\hline Total & & 961 & & & & & \\
\hline
\end{tabular}

of comments per post were significant $\left(c^{2}[\mathrm{df}=14, n=931]=42, p \leq 0.0005\right)$. This indicates a significantly higher level of audience engagement (via comments per post) for photos of taxa such as arachnids, amphibians, echinoderms and mammals.

\section{Videos}

For videos, the most frequently posted taxa were the mammals ( $n=101,28.69 \%)$, cephalopods and insects ( $n=29$ each, $8.24 \%)$, reptiles $(n=24,6.82 \%)$, birds $(n=22,6.25 \%)$, and bony fishes $(n=21,5.97 \%)$ (Table 4$)$. 
Table 4. Number of posts, likes and comments on videos for each taxa, arranged from lowest to highest number of posts per taxa.

\begin{tabular}{|c|c|c|c|c|c|c|c|}
\hline Phylum & Subphylum/Class & $\begin{array}{c}\# \\
\text { posts }\end{array}$ & $\begin{array}{l}\text { \% of } \\
\text { total } \\
\text { posts }\end{array}$ & $\begin{array}{c}\text { Total } \\
\text { views }\end{array}$ & $\begin{array}{c}\text { Views } \\
\text { per post }\end{array}$ & $\begin{array}{c}\text { Total } \\
\text { com- } \\
\text { ments }\end{array}$ & $\begin{array}{c}\text { Comments } \\
\text { per post }\end{array}$ \\
\hline Annelida & Oligochaeta & 1 & $0.28 \%$ & 7733 & 7733.00 & 8 & 8.00 \\
\hline Arthropoda & Hexapoda & 1 & $0.28 \%$ & 11252 & 11252.00 & 5 & 5.00 \\
\hline Arthropoda & Diplopoda & 1 & $0.28 \%$ & 22500 & 22500.00 & 138 & 138.00 \\
\hline Chordata & Hyperoartia & 1 & $0.28 \%$ & 9763 & 9763.00 & 13 & 13.00 \\
\hline Chordata & Myxini & 1 & $0.28 \%$ & 26354 & 26354.00 & 35 & 35.00 \\
\hline Chordata & Protopterus & 1 & $0.28 \%$ & 54159 & 54159.00 & 56 & 56.00 \\
\hline Platyhelminthes & Platyhelminthes & 1 & $0.28 \%$ & 58316 & 58316.00 & 45 & 45.00 \\
\hline Arthropoda & Pycnogonida & 2 & $0.57 \%$ & 27871 & 13935.50 & 70 & 35.00 \\
\hline Cnidaria & Hydrozoa & 2 & $0.57 \%$ & 28814 & 14407.00 & 18 & 9.00 \\
\hline Echinodermata & Asteroidea & 2 & $0.57 \%$ & 17902 & 8951.00 & 20 & 10.00 \\
\hline Echinodermata & Ophiuroidea & 2 & $0.57 \%$ & 151177 & 75588.50 & 371 & 185.50 \\
\hline Annelida & Polychaeta & 3 & $0.85 \%$ & 143568 & 47856.00 & 359 & 119.67 \\
\hline Mollusca & Bivalva & 3 & $0.85 \%$ & 48197 & 16065.67 & 93 & 31.00 \\
\hline Nematoda & Nematoda & 3 & $0.85 \%$ & 59732 & 19910.67 & 41 & 13.67 \\
\hline Rotifera & Rotifera & 3 & $0.85 \%$ & 59097 & 19699.00 & 33 & 11.00 \\
\hline Echinodermata & Holothuroidea & 4 & $1.14 \%$ & 63085 & 15771.25 & 93 & 23.25 \\
\hline Cnidaria & Anthozoa & 7 & $1.99 \%$ & 100033 & 14290.43 & 113 & 16.14 \\
\hline Chordata & Amphibia & 9 & $2.56 \%$ & 216272 & 24030.22 & 579 & 64.33 \\
\hline Cnidaria & Medusozoa & 12 & $3.41 \%$ & 205305 & 17108.75 & 249 & 20.75 \\
\hline Arthropoda & Crustacea & 13 & $3.69 \%$ & 267341 & 20564.69 & 467 & 35.92 \\
\hline Chordata & Chondrichthyes & 13 & $3.69 \%$ & 502221 & 38632.38 & 477 & 36.69 \\
\hline Tardigrada & Tardigrada & 13 & $3.69 \%$ & 285546 & 21965.08 & 632 & 48.62 \\
\hline Arthropoda & Arachnida & 14 & $3.98 \%$ & 554346 & 39596.14 & 2587 & 184.79 \\
\hline Mollusca & Gastropoda & 14 & $3.98 \%$ & 690960 & 49354.29 & 2369 & 169.21 \\
\hline Chordata & Actinopterygii & 21 & $5.97 \%$ & 381297 & 18157.00 & 1047 & 49.86 \\
\hline Chordata & Aves & 22 & $6.25 \%$ & 624148 & 28370.36 & 2621 & 119.14 \\
\hline Chordata & Reptilia & 24 & $6.82 \%$ & 658575 & 27440.63 & 1488 & 62.00 \\
\hline Arthropoda & Insecta & 29 & $8.24 \%$ & 834960 & 28791.72 & 1173 & 40.45 \\
\hline Mollusca & Cephalopoda & 29 & $8.24 \%$ & 827572 & 28536.97 & 1189 & 41.00 \\
\hline Chordata & Mammalia & 101 & $28.69 \%$ & 2373074 & 23495.78 & 8062 & 79.82 \\
\hline Total & & 352 & & & & & \\
\hline
\end{tabular}

As with the photos, several subphyla/classes returned very small numbers of video posts (i.e., less than five). To allow statistical analysis the anthozoa, medusozoa and hydrozoa were combined as the cnidaria (final $n=21$ ); and the asteroidea, holothuroidea and ophiuroidea were combined as the echinodermata (final $n=8$ ). Taxa with fewer than 8 posts were excluded from analysis in order to avoid potential outlier bias. This approach retained $94 \%$ of the original data for statistical analysis.

Chi-square analysis showed that differences in the number of posts between taxa with 8 or more video posts were significant $\left(c^{2}[\mathrm{df}=14, n=331]=321\right.$, $p \leq 0.0005)$. That is, taxa such as mammals, cephalopods, insects and reptiles had significantly more video posts than other taxa. 
Considering only the taxa with more than 8 posts, the videos with the highest number of views were of gastropods (49354 views per post, range 7473 to 147178 views), arachnids (39596 views per post, range 10118 to 84311 views), cartilaginous fish (38 632 views per post, range 3327 to 212882 views), echinoderms (29 021 views per post, range 2645 to 109433 views), and insects (28 792 views per post, range 3349 to 107336 views) (Table 4). Differences in the number of views per post were significant $\left(c^{2}[\mathrm{df}=14, n=331]=41919, p \leq 0.0005\right)$. This indicates a significantly higher level of audience engagement (via views per post) for videos of taxa such as gastropods, arachnids, cartilaginous fish and echinoderms.

The videos with the highest number of comments were of arachnids (185.8 comments per post, range 20 to 495 comments), gastropods (169.2 comments per post, range 6 to 506 comments), birds (119.1 comments per post, range 6 to 856 comments), mammals (79.8 comments per post, range 1 to 1139 comments), and amphibians (64.3 comments per post, range 3 to 335 comments) (Table 4).

Differences in the number of comments per post were significant

$\left(c^{2}[\mathrm{df}=14, n=331]=467, p \leq 0.0005\right)$, indicating a significantly higher level of audience engagement (via comments per post) for videos of taxa such as arachnids, gastropods, birds and mammals.

\section{Sentiment analysis}

A total of 2303 comments were coded across 262 separate posts. Sixty-seven of these posts had less than the proposed ten comments to code. The random selection process resulted in several taxa having very small numbers of posts (i.e., less than five) included in the sentiment analysis. To allow statistical analysis, only those taxa with eight or more posts were included. This retained $93.2 \%$ of the coded posts for statistical analysis.

When only considering those with eight or more posts, the taxa with the highest mean sentiment scores were the cnidaria and tardigrades (0.62 each), the bony fishes (0.51), the cephalopods and amphibians ( 0.49 each). The taxa with the lowest mean sentiment scores (when only considering those with eight or more posts) were the arachnids (0.18), the crustacea $(0.20)$, the insects $(0.31)$, the annelids $(0.33)$ and the mammals (0.39) (Table 5).

Chi-square analysis showed that differences in the sentiment scores between taxa were not significant $\left(c^{2}[\mathrm{df}=14, n=245]=0.58, p \geq 0.2\right)$.

Examples of positive language included 'wow!', 'beautiful', 'love these', 'thanks for the information', thumbs up emoji $\mathcal{L}$ ' emoji . Examples of negative language included 'yuk!', 'the names are difficult to remember', criticisms of the research (e.g. considering it cruel), 'oh my god I hate nature', 'I'm in love with this shark but also terrified of it', vomiting emoji , and scared emojis 8 . Examples of neutral language included 'Merry Christmas' on Christmas Day posts, requests for more information, repeating the content of the post with no sentiment indicated, and references to pop culture with no sentiment indicated (e.g., 'this reminds me of a Daft Punk helmet'). 
Table 5. Sentiment analysis, arranged from lowest to highest mean sentiment score.

\begin{tabular}{|lccc|}
\hline Phylum/Class & $\begin{array}{c}\text { \# coded } \\
\text { posts }\end{array}$ & $\begin{array}{c}\text { Cumulative } \\
\text { sentiment } \\
\text { score }\end{array}$ & $\begin{array}{c}\text { Mean } \\
\text { sentiment } \\
\text { score }\end{array}$ \\
\hline Hyperoartia & 1 & -0.60 & -0.60 \\
Myxini & 1 & -0.60 & -0.60 \\
Pycnogonid & 1 & -0.60 & -0.60 \\
Platyhelminthes & 1 & -0.40 & -0.40 \\
Ctenophora & 1 & 0.10 & 0.10 \\
Arachnid & 12 & 2.13 & 0.18 \\
Crustacea & 10 & 1.98 & 0.20 \\
Insect & 37 & 11.39 & 0.31 \\
Annelid & 8 & 2.67 & 0.33 \\
Tunicate & 2 & 0.70 & 0.35 \\
Nematode & 2 & 0.76 & 0.38 \\
Mammal & 46 & 17.76 & 0.39 \\
Nemertea & 1 & 0.40 & 0.40 \\
Gastropod & 10 & 4.20 & 0.42 \\
Echinoderm & 8 & 3.50 & 0.44 \\
Aves & 29 & 13.58 & 0.47 \\
Chondrichthyes & 10 & 4.80 & 0.48 \\
Reptile & 19 & 9.18 & 0.48 \\
Amphibian & 10 & 4.90 & 0.49 \\
Cephalopod & 12 & 5.90 & 0.49 \\
Actinopterygii & 15 & 7.65 & 0.51 \\
Rotifera & 2 & 1.03 & 0.52 \\
Bivalve & 2 & 1.10 & 0.55 \\
Tardigrade & 5 & 3.10 & 0.62 \\
Cnidaria & 14 & 8.69 & 0.62 \\
Diplopoda & 3 & 2.25 & 0.75 \\
\hline Total & 262 & & \\
\hline
\end{tabular}

A literature review found nine papers that quantify taxonomic bias within published wildlife research [Clark and May, 2002; Cronin et al., 2014; Di Marco et al., 2017; Fazey, Fischer and Lindenmayer, 2005; Lawler et al., 2006;

Martín-López et al., 2009; Rosenthal et al., 2017; Titley, Snaddon and Turner, 2017; Velasco et al., 2015]. The proportions attributed to vertebrate and invertebrate taxa in these nine studies total approximately $82 \%$, with the remainder assumed to be attributed to flora and fungi. As flora and fungi were not included in this study, the results of the literature review were scaled to reflect a $100 \%$ weight and to be a more accurate comparison. On average, $81.69 \%$ focused on vertebrates and $18.30 \%$ focused on invertebrates. Mammals and birds were the most frequently published in wildlife research, with $30.48 \%$ and $30.85 \%$ of published papers respectively. Insects (15.82\%), generalised fish (including sharks, rays, hagfish, lampreys and lungfish) $(7.25 \%)$, reptiles $(4.08 \%)$ and amphibians (3.48\%) received less coverage. A broad category of 'other invertebrates' (i.e., all invertebrates other than insects) was used relatively commonly $(6.46 \%)$ (Table 2$)$. A scatterplot of the two datasets showed a weak positive linear relationship (Figure 1). 


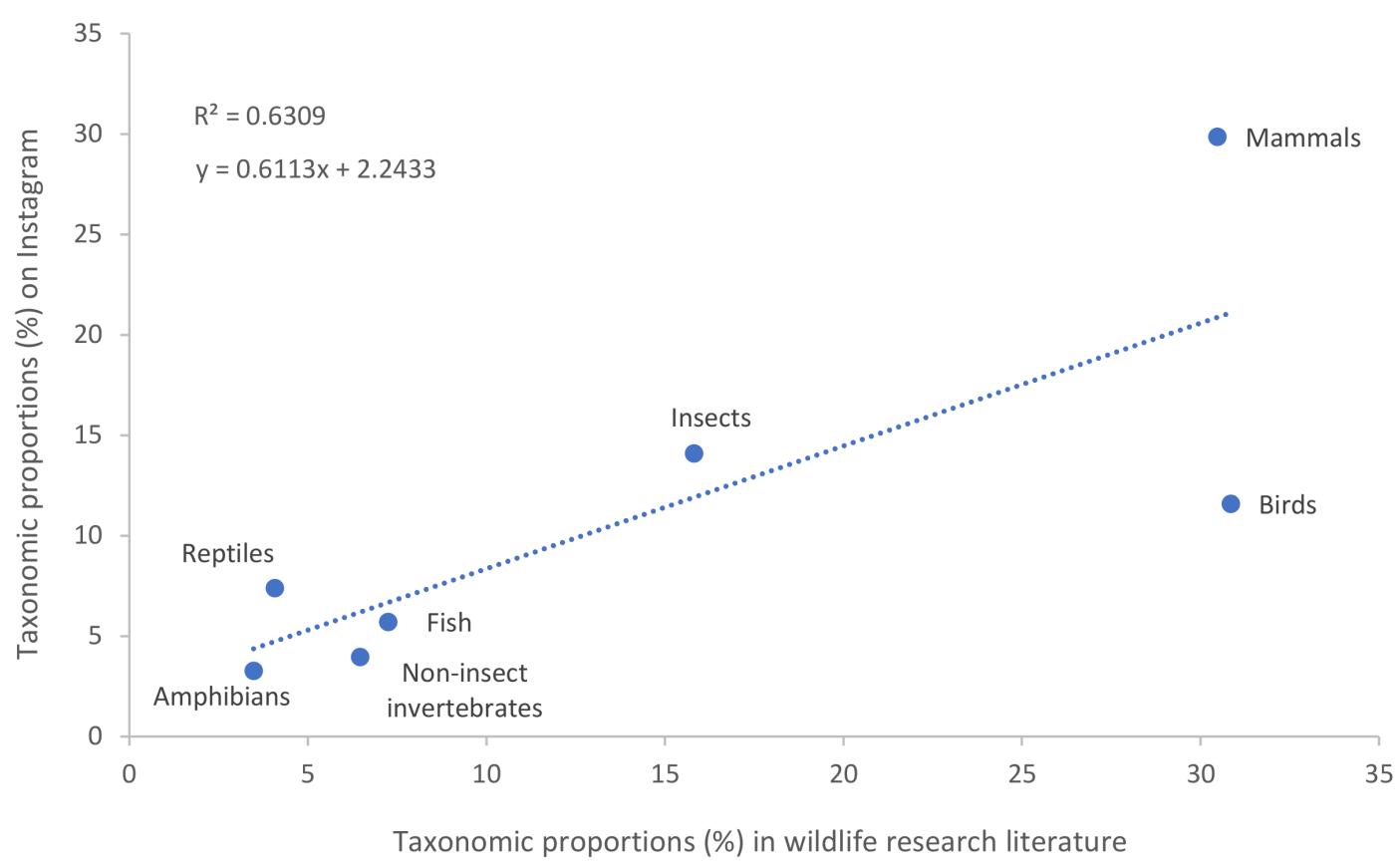

Figure 1. Taxonomic proportions (\%) in wildlife research literature vs. Instagram.

\section{Discussion}

Approximately three out of every five Instagram posts (61.54\%) focused on vertebrates. This is less than the rate of vertebrate bias in wildlife research, which found that on average $81.69 \%$ of published papers focused on vertebrates [Table 2: Clark and May, 2002; Cronin et al., 2014; Di Marco et al., 2017; Fazey, Fischer and Lindenmayer, 2005; Lawler et al., 2006; Martín-López et al., 2009; Rosenthal et al., 2017; Titley, Snaddon and Turner, 2017; Velasco et al., 2015]. Plotting the two datasets showed a weak positive linear relationship (Figure 1), likely to be from social media managers drawing on published research for material. The results of this study also found a dominance of Instagram posts about mammals, insects and birds which was correlated in the literature on taxonomic bias. Two noticeable differences were seen in the proportion of posts and papers on birds $(11.58 \%$ of posts vs. $30.85 \%$ of papers) and non-insect vertebrates $(24.37 \%$ of posts vs. $6.46 \%$ of papers). The larger proportion of non-insect invertebrates being posted on Instagram may be a result of social media managers recognising the appeal of these taxa with their audiences.

This appeal is reflected in the results of this study. The taxa with the most likes per posts (among photos) were the cephalopods and the taxa with the most views per posts (among videos) were the gastropods. In fact, four of the five most-viewed taxa among videos were invertebrates (gastropods, arachnids, echinoderms and insects). These results compare with McClain [2019], who found cephalopods and other species not traditionally considered 'charismatic megafauna' to be among the most liked images of marine animals on Facebook. It should be noted that as McClain [2019] focused only on marine taxa, this comparison is limited. Other studies have found stronger audience preference for mammals [Hausmann et al., 2018; Kidd et al., 2018; Llewellyn and Rose, 2021; Rose, Hunt and Riley, 2018]. However, these studies also found that several non-taxonomic variables can influence audience engagement, including the use of colourful or novel material, content that evokes awe, or positive or emotive reactions [McClain, 2019] or the 
promotion of interesting behavioural or physical traits [Kidd et al., 2018]. This may explain why the photo with the greatest number of likes in this study was of a snapping turtle persevering under a heavy load of mud and grass (Science Alert, August 21) or the popularity among CSIRO followers of a comically sad-looking black rain frog (Breviceps fuscus) (CSIRO, November 5).

Theories of user-gratification would predict social media followers to engage more strongly with posts that please them [Dolan et al., 2016]. In the case of wildlife, this is strongly influenced by appearance, with humans showing a strong preference for 'charismatic megafauna'- animals that are large-bodied [Hausmann et al., 2018; Roberge, 2014], biologically or behaviourally similar to humans [Batt, 2009; Martín-López et al., 2009], and neotenous with proportionately large heads and large forward-facing eyes [Estren, 2012]. Indeed, despite being the second most-frequently posted taxa in this study insects had low likes per post and a relatively low sentiment score. Interestingly, among the most-liked taxa for photos and the most-viewed taxa for videos were the arachnids. Arachnids also enjoyed the highest number of comments for both photos and videos. Several of the accounts examined in this study repeatedly posted images of peacock spiders, likely due to the beauty of their colours and charming dance moves, which may have influenced the high number of likes and views for arachnids. However they also had one of the lowest sentiment scores of any taxa, resulting from entrenched negativity towards spiders expressed within the comments (such as "That is a beautiful shade of blue! But if I saw that, up close to me... I would freak out!" Science Alert, June 16). This highlights the deeply ingrained negative associations held in society towards particular taxa, including insects and spiders [Sumner, Law and Cini, 2018], that can influence the direction and level of online audience engagement with them [Lennox et al., 2020].

Mammals also had high numbers of likes and comments but a relatively low sentiment score. This may have been influenced by the text on the post rather than the image itself, with the most strongly negative mammalian sentiment scores being recorded for a macaque being released from laboratory experiments (Science Magazine, December 10), the extinct thylacine (IFL Science, May 24), dogs sledding in climate change-induced glacial melt (IFL Science, June 19) and a sloth living in the filth of a drop toilet (Science Alert, December 5). Other studies have found text to influence public engagement with Instagram posts [Jarreau, Dahmen and Jones, 2019], suggesting that both image and textual content should be taken into account when examining audience engagement on Instagram. Audience sentiment and engagement with online content can also be influenced by variables such as how close or far away the subject is [Jarreau, Dahmen and Jones, 2019], the tone (humorous or serious) of the post [Lenda et al., 2020], novelty [Kidd et al., 2018; McClain, 2019] and entertainment value [Lessard, Whiffin and Wild, 2017], length [Llewellyn and Rose, 2021], whether it contains breaking news [Jarreau, Dahmen and Jones, 2019; Lessard, Whiffin and Wild, 2017], as well as significant events like the rediscovery of species thought to be extinct [Lennox et al., 2020]. In their search for the most 'Instagrammable' bird, Thömmes and Hayn-Leichsenring [2021, p. 2] found that blue colours as well as "interestingness, idiosyncrasy, and the situational context all play their part in the aesthetic appeal of bird photos to the human observer". Examining these parameters in depth was beyond the scope of this study but would be useful to include in future research on trends of taxonomic bias on Instagram. Ultimately, statistical analysis showed that differences in 
sentiment scores across taxa in this study were not significant, which may indicate that larger sample sizes or classifying more finely than the phyla/class are needed to fully reflect differences between the taxa.

The data used in this study carry some inherent limitations. For example, several images were repeated, at times by the same account (usually high-performing images reposted several months later) and others across multiple accounts (such as the winning images from high profile nature photography competitions). Similarly, CSIRO featured an image of a wombat every Wednesday ('Wombat Wednesday'), which increased the number of mammals in the results. In addition, over half ( $n=701,53.3 \%$ ) of all the posts recorded were from one account (IFL Science). This means that any biases in that account are likely to influence the results. The data were also drawn from a mix of academic and news/popular oriented Instagram accounts. For example, the Science Magazine, New Scientist and Nature Portfolio accounts primarily communicated academic information, the IFL Science and PopSci accounts were often focused on popular science content and the CSIRO and Science Alert accounts contained a mix of academic and popular science. This was intended to capture a broad science-interested audience base but it does mean that examining nuances between different audience types was not possible with this study. Nevertheless, the seven accounts chosen are global in focus and dedicated to disseminating scientific information and news about multiple taxa. As such, they are likely to be among the most representative options for studying taxonomic trends on Instagram.

The high popularity of several non-insect invertebrates in this work suggests a mismatch between the preferences of science-seeking audiences and the information being offered to them. As McClain [2019, p. 13] states, "traditional definitions of 'charismatic megafauna' and what organisms the public most engage with may be incorrect". Encouragingly, the substantially greater amount of non-insect invertebrate content in this study than that found in baseline taxonomic research may indicate that science communicators on Instagram are beginning to recognise and respond to the preferences of their audiences. However, posts on mammals and birds continue to dominate Instagram science content, suggesting that more could be done to search for and promote news and information about other taxa in order to achieve greater taxonomic balance. Considering the current and accelerating loss of global biodiversity [Ceballos et al., 2015; Dirzo and Raven, 2003], and the role of public opinion in conservation efforts [Davies et al., 2018; Martín-López et al., 2009; Troudet et al., 2017], communicating with the public based on terms of conservation need rather than historic and potentially incorrect assumptions of species popularity [Davies et al., 2018; McClain, 2019] is urgently required.

Conclusions

The results of this study offer a first insight into the taxonomic preferences of science-seeking audiences on Instagram and therefore allows science communicators to design better informed and more engaging content. At the same time, this could counteract prevailing trends of taxonomic bias in publicly available information and help to improve public perceptions and conservation outcomes of traditionally under-represented species like invertebrates. 
Acknowledgments The author wishes to thank Dr. Alistair Hobday and Dr. Craig Norris for assistance with project design and manuscript review. The author would also like to thank the anonymous reviewers whose feedback improved the quality of the final manuscript.

\section{Declaration of} interest

Ethics approval
The author declares no conflicts of interest.

Ethics approval for this study was obtained in August 2020 from the Tasmanian Social Sciences Human Research Ethics Committee, project ID 23153.

Auxier, B. and Anderson, M. (2021). 'Social media use in 2021'. Pew Research Center. URL: https://www . pewresearch.org/internet/2021/04/07/social-media-us e-in-2021/ (visited on 18th April 2021).

Baker, M. J., Williams, L. F., Lybbert, A. H. and Johnson, J. B. (2012). ‘How ecological science is portrayed in mass media'. Ecosphere 3 (1), 9. https://doi.org/10.1890/es11-00238.1.

Barel-Ben David, Y., Garty, E. S. and Baram-Tsabari, A. (2020). 'Can scientists fill the science journalism void? Online public engagement with science stories authored by scientists'. PLoS ONE 15 (1), e0222250. https://doi.org/10.1371/journal.pone. 0222250.

Batt, S. (2009). 'Human attitudes towards animals in relation to species similarity to humans: a multivariate approach'. Bioscience Horizons 2 (2), pp. 180-190. https://doi.org/10.1093/biohorizons/hzp021.

Ceballos, G., Ehrlich, P. R., Barnosky, A. D., García, A., Pringle, R. M. and Palmer, T. M. (2015). 'Accelerated modern human-induced species losses: entering the sixth mass extinction'. Science Advances 1 (5), e1400253. https://doi.org/10.1126/sciadv. 1400253.

Clark, J. A. and May, R. M. (2002). 'Taxonomic bias in conservation research'. Science 297 (5579), pp. 191-192. https://doi.org/10.1126/science.297.5579.191b.

Clucas, B., McHugh, K. and Caro, T. (2008). 'Flagship species on covers of US conservation and nature magazines'. Biodiversity and Conservation 17 (6), pp. 1517-1528. https://doi.org/10.1007/s10531-008-9361-0.

Collins, K., Shiffman, D. and Rock, J. (2016). 'How are scientists using social media in the workplace?' PLoS ONE 11 (10), e0162680. https://doi.org/10.1371/journal . pone.0162680.

Cronin, D. T., Owens, J. R., Choi, H., Hromada, S., Malhotra, R., Roser, F. and Bergl, R. A. (2014). 'Where has all our research gone? A 20-year assessment of the peer-reviewed wildlife conservation literature'. International Journal of Comparative Psychology 27 (1), pp. 101-116. https://doi.org/10.46867/ijcp.2014.27.01.02.

Davies, T., Cowley, A., Bennie, J., Leyshon, C., Inger, R., Carter, H., Robinson, B., Duffy, J., Casalegno, S., Lambert, G. and Gaston, K. (2018). 'Popular interest in vertebrates does not reflect extinction risk and is associated with bias in conservation investment'. PLoS ONE 13 (9), e0203694.

https://doi.org/10.1371/journal pone.0203694. 
Di Marco, M., Chapman, S., Althor, G., Kearney, S., Besancon, C., Butt, N., Maina, J. M., Possingham, H. P., Rogalla von Bieberstein, K., Venter, O. and Watson, J. E. M. (2017). 'Changing trends and persisting biases in three decades of conservation science'. Global Ecology and Conservation 10, pp. 32-42. https://doi.org/10.1016/j.gecco.2017.01.008.

Di Minin, E., Tenkanen, H. and Toivonen, T. (2015). 'Prospects and challenges for social media data in conservation science'. Frontiers in Environmental Science 3, 63. https://doi.org/10.3389/fenvs.2015.00063.

Dirzo, R. and Raven, P. H. (2003). 'Global state of biodiversity and loss'. Annual Review of Environment and Resources 28, pp. 137-167. https://doi.org/10.1146/annurev . energy . 28.050302.105532.

Dolan, R., Conduit, J., Fahy, J. and Goodman, S. (2016). 'Social media engagement behaviour: a uses and gratifications perspective'. Journal of Strategic Marketing 24 (3-4), pp. 261-277. https://doi.org/10.1080/0965254x.2015.1095222.

Donaldson, M. R., Burnett, N. J., Braun, D. C., Suski, C. D., Hinch, S. G., Cooke, S. J. and Kerr, J. T. (2017). 'Taxonomic bias and international biodiversity conservation research'. FACETS 1, pp. 105-113. https://doi.org/10.1139/facets-2016-0011.

dos Santos, J. W., Correia, R. A., Malhado, A. C. M., Campos-Silva, J. V., Teles, D., Jepson, P. and Ladle, R. J. (2020). 'Drivers of taxonomic bias in conservation research: a global analysis of terrestrial mammals'. Animal Conservation 23 (6), pp. 679-688. https://doi.org/10.1111/acv. 12586.

Estren, M. J. (2012). 'The neoteny barrier: seeking respect for the non-cute'. Journal of Animal Ethics 2 (1), pp. 6-11. https://doi.org/10.5406/janimalethics.2.1.0006.

Fazey, I., Fischer, J. and Lindenmayer, D. B. (2005). 'What do conservation biologists publish?' Biological Conservation 124 (1), pp. 63-73. https://doi.org/10.1016/j.biocon.2005.01.013.

Funk, C., Gottfried, J. and Mitchell, A. (2017). 'Science news and information today'. Pew Research Center. URL: https: //www. journalism.org/2017/09/20/s cience-news-and-information-today/ (visited on 18th April 2021).

Hansen, A. and Machin, D. (2013). 'Researching visual environmental communication'. Environmental Communication 7 (2), pp. 151-168. https://doi.org/10.1080/17524032.2013.785441.

Hausmann, A., Toivonen, T., Slotow, R., Tenkanen, H., Moilanen, A., Heikinheimo, V. and Di Minin, E. (2018). 'Social media data can be used to understand tourists' preferences for nature-based experiences in protected areas'. Conservation Letters 11 (1), e12343. https://doi.org/10.1111/conl.12343.

Jarić, I., Correia, R. A., Roberts, D. L., Gessner, J., Meinard, Y. and Courchamp, F. (2019). 'On the overlap between scientific and societal taxonomic attention Insights for conservation'. Science of the Total Environment 648, pp. 772-778. https://doi.org/10.1016/j.scitotenv.2018.08.198.

Jarreau, P. B., Dahmen, N. S. and Jones, E. (2019). 'Instagram and the science museum: a missed opportunity for public engagement'. JCOM 18 (02), A06. https://doi.org/10.22323/2.18020206.

Kidd, L. R., Gregg, E. A., Bekessy, S. A., Robinson, J. A. and Garrard, G. E. (2018). 'Tweeting for their lives: visibility of threatened species on Twitter'. Journal for Nature Conservation 46, pp. 106-109.

https://doi.org/10.1016/j.jnc.2018.10.001. 
Lawler, J. J., Aukema, J. E., Grant, J. B., Halpern, B. S., Kareiva, P., Nelson, C. R., Ohleth, K., Olden, J. D., Schlaepfer, M. A., Silliman, B. R. and Zaradic, P. (2006). 'Conservation science: a 20-year report card'. Frontiers in Ecology and the Environment 4 (9), pp. 473-480.

https://doi .org/10.1890/1540-9295(2006)4 [473: csayrc] 2.0.co;2.

Lenda, M., Skórka, P., Mazur, B., Sutherland, W., Tryjanowski, P., Moroń, D., Meijaard, E., Possingham, H. P. and Wilson, K. A. (2020). 'Effects of amusing memes on concern for unappealing species'. Conservation Biology 34 (5), pp. 1200-1209. https://doi.org/10.1111/cobi.13523.

Lennox, R. J., Veríssimo, D., Twardek, W. M., Davis, C. R. and Jarić, I. (2020). 'Sentiment analysis as a measure of conservation culture in scientific literature'. Conservation Biology 34 (2), pp. 462-471. https://doi.org/10.1111/cobi.13404.

Lessard, B. D., Whiffin, A. L. and Wild, A. L. (2017). 'A guide to public engagement for entomological collections and natural history museums in the age of social media'. Annals of the Entomological Society of America 110 (5), pp. 467-479. https://doi.org/10.1093/aesa/sax058.

Llewellyn, T. and Rose, P. E. (2021). 'Education is entertainment? Zoo science communication on YouTube'. Journal of Zoological and Botanical Gardens 2 (2), pp. 250-264. https://doi.org/10.3390/jzbg2020017.

Lörcher, I. and Taddicken, M. (2017). ‘Discussing climate change online. Topics and perceptions in online climate change communication in different online public arenas'. JCOM 16 (02), A03. https: //doi .org/10.22323/2.16020203.

Lunney, D. and Matthews, A. (2003). "“Throw a koala on the barbie" (Daily Telegraph 15 July 1997): an analysis of wildlife reporting in two daily newspapers'. Australian Zoologist 32 (2), pp. 288-297. https://doi.org/10.7882/az.2003.013.

Lyngdoh, S., Dixit, D. and Sinha, B. C. (2017). 'Print mass media coverage of wildlife in the developing world'. Current Science 113 (4), pp. 564-570. URL: https://www . jstor.org/stable/26293887.

Martín-López, B., Montes, C., Ramírez, L. and Benayas, J. (2009). ‘What drives policy decision-making related to species conservation?' Biological Conservation 142 (7), pp. 1370-1380. https : //doi.org/10.1016/ j. biocon.2009.01.030.

McClain, C. R. (2019). 'Likes, comments, and shares of marine organism imagery on Facebook'. PeerJ 7, e6795. https://doi.org/10.7717/peerj . 6795.

McKinnon, M., Howes, J., Leach, A. and Prokop, N. (2018). 'Perils and positives of science journalism in Australia'. Public Understanding of Science 27 (5), pp. 562-577. https://doi.org/10.1177/0963662517701589.

Mohammad, S. M. (2010). NRC Word-Emotion Association Lexicon v0.92. National Research Council of Canada.

URL: https://saifmohammad.com/WebPages/NRC-Emotion-Lexicon.htm (visited on 18th July 2021).

Papworth, S. K., Nghiem, T. P. L., Chimalakonda, D., Posa, M. R. C., Wijedasa, L. S., Bickford, D. and Carrasco, L. R. (2015). 'Quantifying the role of online news in linking conservation research to Facebook and Twitter'. Conservation Biology 29 (3), pp. 825-833. https://doi.org/10.1111/cobi.12455.

Pavelle, S. and Wilkinson, C. (2020). 'Into the digital wild: utilizing Twitter, Instagram, YouTube, and Facebook for effective science and environmental communication'. Frontiers in Communication 5, 575122.

https://doi .org/10.3389/f comm.2020.575122. 
Pew Research Center (2021). Social media fact sheet.

URL: https://www . pewresearch .org/internet/fact-sheet/social-media/.

Roberge, J.-M. (2014). 'Using data from online social networks in conservation science: which species engage people the most on Twitter?' Biodiversity and Conservation 23 (3), pp. 715-726.

https://doi.org/10.1007/s10531-014-0629-2.

Rose, P. E., Hunt, K. A. and Riley, L. M. (2018). 'Animals in an online world; an evaluation of how zoological collections use social media'. Journal of Zoo and Aquarium Research 6 (2), pp. 57-62. https://doi.org/10.19227/jzar.v6i2.324.

Rosenthal, M. F., Gertler, M., Hamilton, A. D., Prasad, S. and Andrade, M. C. B. (2017). 'Taxonomic bias in animal behaviour publications'. Animal Behaviour 127, pp. 83-89. https://doi.org/10.1016/j . anbehav .2017.02.017.

Roskov, Y., Ower, G., Orrell, T., Nicolson, D., Bailly, N., Kirk, P. M., Bourgoin, T., DeWalt, R. E., Decock, W., van Nieukerken, E., Zarucchi, J. and Penev, L., eds. (2019). Species 2000 E ITIS Catalogue of Life: 2019 Annual Checklist. URL: http://www . catalogueoflife .org/annual-checklist/2019.

Russmann, U. and Svensson, J. (2016). 'Studying organizations on Instagram'. Information 7 (4), 58. https://doi .org/10.3390/inf 07040058.

Shearer, E. (2021). 'More than eight-in-ten Americans get news from digital devices'. Pew Research Center.

URL: https://www . pewresearch .org/fact-tank/2021/01/12/more-than-eigh t-in-ten-americans-get-news-from-digital-devices/ (visited on 18th April 2021).

Statista (2021). Most popular social networks worldwide as of April 2021, ranked by number of active users. URL: https://www. statista.com/statistics/272014/gl obal-social-networks-ranked-by-number-of-users/.

Sumner, S., Law, G. and Cini, A. (2018). 'Why we love bees and hate wasps'. Ecological Entomology 43 (6), pp. 836-845. https://doi.org/10.1111/een.12676.

Takahashi, B. and Tandoc, E. C. (2016). 'Media sources, credibility, and perceptions of science: learning about how people learn about science'. Public Understanding of Science 25 (6), pp. 674-690. https: //doi .org/10.1177/0963662515574986.

Thömmes, K. and Hayn-Leichsenring, G. (2021). 'What Instagram can teach us about bird photography: the most photogenic bird and color preferences'. i-Perception 12 (2). https: //doi .org/10.1177/20416695211003585.

Titley, M. A., Snaddon, J. L. and Turner, E. C. (2017). 'Scientific research on animal biodiversity is systematically biased towards vertebrates and temperate regions'. PLoS ONE 12 (12), e0189577. https://doi.org/10.1371/journal.pone.0189577.

Toivonen, T., Heikinheimo, V., Fink, C., Hausmann, A., Hiippala, T., Järv, O., Tenkanen, H. and Di Minin, E. (2019). 'Social media data for conservation science: a methodological overview'. Biological Conservation 233, pp. 298-315. https://doi.org/10.1016/j.biocon.2019.01.023.

Troudet, J., Grandcolas, P., Blin, A., Vignes-Lebbe, R. and Legendre, F. (2017). 'Taxonomic bias in biodiversity data and societal preferences'. Scientific Reports 7, 9132. https://doi.org/10.1038/s41598-017-09084-6.

Velasco, D., García-Llorente, M., Alonso, B., Dolera, A., Palomo, I., Iniesta-Arandia, I. and Martín-López, B. (2015). 'Biodiversity conservation research challenges in the 21st century: a review of publishing trends in 2000 and 2011'. Environmental Science \& Policy 54, pp. 90-96. https://doi.org/10.1016/j. envsci.2015.06.008. 
Veríssimo, D., Vaughan, G., Ridout, M., Waterman, C., MacMillan, D. and Smith, R. J. (2017). 'Increased conservation marketing effort has major fundraising benefits for even the least popular species'. Biological Conservation 211, Part A, pp. 95-101. https://doi.org/10.1016/j.biocon.2017.04.018. Walsh, J. C., Watson, J. E. M., Bottrill, M. C., Joseph, L. N. and Possingham, H. P. (2013). 'Trends and biases in the listing and recovery planning for threatened species: an Australian case study'. Oryx 47 (1), pp. 134-143. https://doi.org/10.1017/s003060531100161x.

Author

Grace Heathcote has a Masters of Applied Science from James Cook University, Queensland, and is completing a Masters of Strategic Communications at the University of Tasmania. She is the Science Communication Coordinator for The Ecological Society of Australia. E-mail: grace.barker@utas.edu.au.

How to cite

Heathcote, G. (2021). 'Animals of Instagram: taxonomic bias in science communication online'. JCOM 20 (04), A10. https:/ / doi.org/10.22323/2.20040210. 